\title{
An examination of the impact of five grade- crossing safety factors on driver decision making
}

\author{
Michelle Yeh, Jordan Multer \& Thomas Raslear
}

To cite this article: Michelle Yeh, Jordan Multer \& Thomas Raslear (2016) An examination of the impact of five grade-crossing safety factors on driver decision making, Journal of Transportation Safety \& Security, 8:sup1, 19-36, DOI: 10.1080/19439962.2014.959584

To link to this article: http://dx.doi.org/10.1080/19439962.2014.959584

Accepted author version posted online: 11

Sep 2014.

Published online: 11 Sep 2016.

Submit your article to this journal

山 Article views: 19

View related articles $₫$

View Crossmark data $\asymp$ 


\title{
An examination of the impact of five grade-crossing safety factors on driver decision making
}

\author{
Michelle Yeh ${ }^{\mathrm{a}}$, Jordan Multer ${ }^{\mathrm{a}}$, and Thomas Raslear ${ }^{\mathrm{b}}$ \\ aU.S. Department of Transportation, John A. Volpe National Transportation Systems Center, Cambridge, \\ Massachusetts, USA; ${ }^{b}$ Federal Railroad Administration, Washington, D.C., USA
}

\begin{abstract}
The authors applied signal detection theory to model the impact of five grade-crossing safety factors to understand their impact on driver decision making. The safety factors were improving commercial motor vehicle (CMV) driver safety through federal regulations, increasing locomotive conspicuity with alerting lights, increasing locomotive conspicuity with reflectors, increasing sight lines, and improving warning device reliability. The authors estimated sensitivity and bias for eight warning devices associated with each safety factor. The authors also calculated the proportion of variance accounted for by each safety factor and device type to examine the reliability of each on grade-crossing safety. Driver decision making improved due to the warning device type and the introduction of the safety factor. Of the two, warning devices exerted the most impact because they encouraged drivers to stop at grade crossings. Regulations to improve CMV driver safety, alerting lights, sight lines, and reflectors were generally equally effective in improving grade-crossing safety. A comparison of the results from the descriptive model to that produced by a more traditional accident analysis suggest that examination of accident frequency alone may minimize the impact of important safety factors and emphasizes the need to consider accident frequency with respect to human behavioral metrics.
\end{abstract}

\section{KEYWORDS}

grade crossing; safety factors; countermeasures; driver behavior; decision making; signal detection theory

\section{Introduction}

The traditional "three E" approach focusing on education, enforcement, and engineering has been effective in reducing grade-crossing fatalities, but driver error and poor judgment continue to be factors in grade-crossing accidents (Office of the Inspector General, 2004). Drivers' motivations for committing a violation are not easily captured by the three E's but are an important consideration for understanding noncompliance. For this reason, the U.S. Federal Railroad Administration (FRA)

CONTACT Michelle Yeh michelle.yeh@faa.gov E AIR-134 Systems Integration Section, Federal Aviation Administration, 950 L'Enfant Plaza, Washington, DC 20024, USA.

This article not subject to United States copyright law. 
sought a better understanding of driver decision making at highway-railroad grade crossings. In response, we were interested in modeling driver decision-making strategies to evaluate the success of various countermeasures.

We chose signal detection theory (SDT) as it provides a way to examine drivers' decisions with respect to the detectability of the train (sensitivity, $d^{\prime}$ ) and to attitudinal or motivational factors that may influence a driver's criteria for judgment (bias, $\beta$ ). Sensitivity and bias influence the decision to stop or proceed at the highway-railroad grade crossing. SDT describes the operator's ability to detect a signal in a background of noise as a discrete choice task. In SDT, there are two states of the world-signal and noise-and two possible responses: "Yes, I detect a signal" and "No, I do not" (see Egan, 1975; Green \& Swets, 1966, for more information). The signal and noise distributions are described as two theoretic normal distributions to capture the different perceptual magnitudes from one presentation to another, as shown in Figure 1.

In the grade-crossing context, the train serves as the signal, and it provides visual, auditory, and even tactile cues as to its approach (e.g., alerting lights, train horn, vibration). The signal distribution on the right in Figure 1 represents the probability that a train is approaching the crossing whereas the noise distribution on the left represents the probability that there is no train. Other information from the surrounding environment also create noise that competes with the signal, making the signal more difficult to detect (e.g., flashing lights at the crossing, sounds from inside the vehicle). Sensitivity $\left(d^{\prime}\right)$ reflects one's ability to discriminate between signal and noise; sensitivity is described as the difference between the means of the signal and noise distributions. A driver can more easily detect whether a train is approaching when the signal and noise distributions are farther apart. Bias $(\beta)$ reflects a driver's tendency to stop or proceed, and it is depicted by the solid gray vertical line in the figure. A shift to the left demonstrates conservative behavior, that is, the driver is more likely to respond "stop."

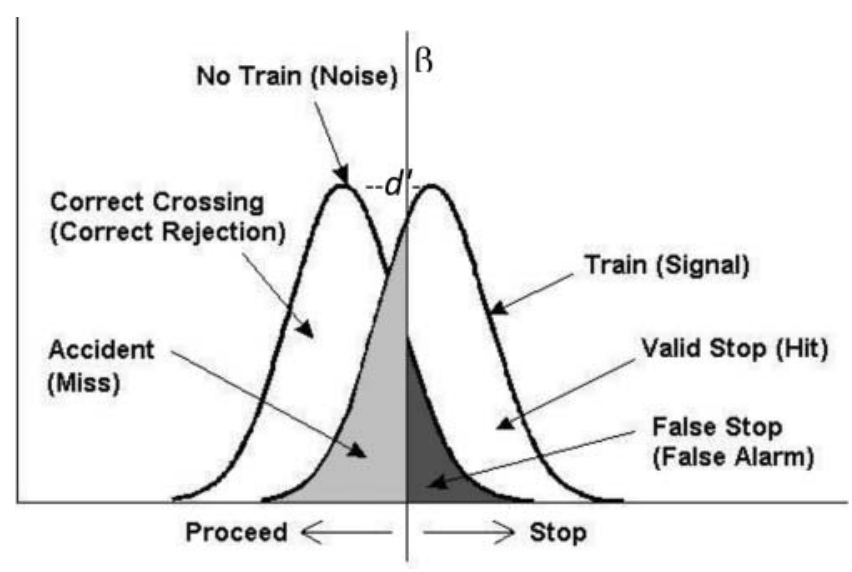

Figure 1. Signal and noise probability distributions. 
Table 1. Signal-response matrix for a driver at a grade crossing.

\begin{tabular}{|c|c|c|c|}
\hline & & \multicolumn{2}{|c|}{ State of the World } \\
\hline & & Train is Close & Train is not Close \\
\hline \multirow[t]{2}{*}{ Driver Response } & Yes $(\text { Stop) })^{\mathrm{a}}$ & Valid Stop ${ }^{\mathrm{a}}$ (driver stops at crossing) & $\begin{array}{l}\text { False Stop }{ }^{\text {a }} \text { (driver stops } \\
\text { unnecessarily) }\end{array}$ \\
\hline & No (Proceed) ${ }^{\mathrm{a}}$ & Accident $^{\mathrm{a}}$ (driver does not stop) & $\begin{array}{l}\text { Correct Crossing }{ }^{\text {a }} \text { (driver safely } \\
\text { crosses tracks) }\end{array}$ \\
\hline
\end{tabular}

${ }^{\text {a }}$ The impact of compliant behavior at a grade crossing.

In our SDT model, there are two states of the world: a train approaches the grade crossing or a train is not approaching the grade crossing. The driver can then respond in one of two ways: stop or proceed. This situation creates four decision-event-related outcomes, as described by the signal-response matrix in Table 1. The impact of compliant behavior at a grade crossing is indicated by the asterisk in each of the four cells. A valid stop describes the decision to stop when a train is close, that is, approaching the grade crossing; this is considered a hit in SDT. A correct crossing is the decision to proceed when a train is not approaching, a correct rejection in SDT. In some cases, a driver may think a train is approaching when one is not and stop unnecessarily, a false alarm in SDT and characterized here as a false stop. This cautious behavior, which may seem desirable, could actually increase the potential for an accident with a close-following vehicle (Mortimer, 1988). Of concern is the potential for an accident when the driver fails to stop for an approaching train. In the SDT framework, this is described as a miss. Note that the four outcomes are determined by the location of the criterion on the signalnoise distribution shown in Figure 1 and not by driver response to the warning device at the grade crossing.

In one application of SDT, Raslear (1996) examined the effectiveness of eight grade-crossing warning devices to determine whether they were effective because they increased drivers' sensitivity by increasing the signal-to-noise ratio, or because they improved bias and encouraged drivers to stop (bias), or because of some combination of the two components. The data used in the analysis was from a single year, 1986. Four of the devices were passive warning systems, which alert the driver to watch out for trains, but do not provide any indication of the presence or approach of a train. These passive warnings included no protection, the crossbuck, stop sign, or other signs or signals. Four devices were active warning systems that provide a signal to the driver when a train is approaching. The active warnings were gates and flashing lights, flashing lights only, highway traffic signals, and special warning devices. As part of the analysis, Raslear (1996) developed an estimation of device effectiveness for each warning device as a ratio of the accident risk at a grade crossing relative to the observed probability of an accident that occurred in 1986. The accident risk was defined as the probability that a train and a highway vehicle will be in the grade crossing during any one-minute observation period. The observed probability of an accident at a grade crossing was defined as the 
number of accidents per crossing per train per highway vehicle per minute (accidents/crossing/train/car/minute).

In 1986, 5,710 accidents occurred at 192,454 grade crossings (approximately 0.030 accidents/crossing). Raslear's (1996) analysis showed that warning devices were effective primarily because they encouraged drivers to stop. Bias was highly correlated with device effectiveness (for gates $\beta^{1}=.001$, for stop signs, $\beta=8.24$ ), accounting for approximately $60 \%$ of the variance in the effectiveness of the devices. Not surprisingly, active warning devices were more effective than passive warning devices; grade crossings protected with gates had the highest effectiveness of all the warning systems, whereas grade crossings with no protection were the least effective. In fact, the data indicated that drivers were more likely to proceed than to stop when grade crossings had no protection at all. Driver sensitivity was relatively high overall and did not vary much across the eight warning devices, suggesting that the train presents an easily detectable signal.

Yeh et al. (2009) updated the analysis conducted by Raslear (1996) using data from 2006 and examined the change in grade-crossing safety over the 20 -year time period. In that time, the number of accidents dropped by more than $50 \%$, with 2,387 accidents at 139,886 grade crossings in 2006 (approximately 0.017 accidents per crossing). During the same time period, exposure increased; the total trains per day at a grade crossing increased by $125 \%$, and the average annual daily traffic (AADT) increased by $64 \%$. The analysis showed that bias changed by almost 50 fold, dropping from 1.45 in 1986 to 0.03 in 2006. Drivers became more conservative in their decisions at grade crossings, and this inclination to stop at grade crossings played a large role in improving the effectiveness of grade-crossing warning devices by an order of magnitude. Sensitivity of the warning devices increased only slightly but significantly, from 6.95 in 1986 to 7.21 in 2006. This change, though small, also contributed to reducing the accident risk.

The analysis conducted by Yeh et al. (2009) did not speak to what factors led to the improvements in grade-crossing safety. In one such study, Horton et al. (2008) attempted to measure the reductions in incidents attributable to "successful" safety factors between 1994 to 2003 . Horton et al. selected the following five safety factors from a greater set of safety programs via literature reviews and group discussions with subject matter experts:

- Improving commercial motor vehicle (CMV) driver safety (e.g., through 64 CFR $\oint \S 383,384)^{2}$

- Improving locomotive conspicuity through the use of alerting lights

- Improving the reliability of motor vehicles

- Increasing sight lines

- Improving warning device reliability.

Horton et al. estimated "success" for each safety factor by comparing the percentage of incidents from 1994 through 2003 that could be attributed to a safety factor in each year and measuring the percent reduction in incidents. An incident was associated with one or more safety factors by using information provided in 
the grade crossing accident reports recorded in the FRA Highway-Rail Grade Crossing Accident/Incident database (http://safetydata.fra.dot.gov). This database contains details on accidents that occurred at a highway-rail grade crossing for each calendar year, such as information on the grade crossing itself (e.g., the type(s) of warning device at the grade crossing and whether the warning device was functioning, sight obstructions at the grade crossing), the type of vehicle(s) involved, and the type of accident (i.e., whether the vehicle struck the train or the train struck the vehicle). Note that the data fields in the FRA Grade Crossing Accident/Incident database describing an accident can cite several factors; one accident could be attributed to multiple safety factors. For example, an accident that involved a motor vehicle that was stalled on the tracks and was hit by a train would be included in the accident count for two of the safety factors listed above: "improving locomotive conspicuity through the use of alerting lights" and "improving the reliability of motor vehicles." Thus, to prevent overestimation of the effect of a safety factor, Horton et al. isolated the effect of each safety factor by classifying each incident as being attributable to one safety factor, more than one safety factor, or none of the safety factors. The impact and percent reduction for each safety factors was then calculated using only a count of those incidents attributable to one safety factor only. Table 2 shows the percent reduction of incidents reported by Horton et al.

The results indicated that the cumulative percent reduction for all five factors totaled 58\%. Two factors accounted for approximately $48 \%$ of the reduction in accidents: "regulations to improve CMV driver safety" and "increasing locomotive conspicuity through the use of alerting lights. The other three factors each accounted for a $3 \%$ to $4 \%$ change in the 10 -year period examined.

We wanted to use the same approach developed by Horton et al. (2008) but focus on the impact of those same programs in terms of their effect on driver decision making. We were particularly interested in the safety factors that were identified by Horton et al., which were the result of U.S. Department of Transportation (DOT) programs designed to reduce grade-crossing accidents. It is important to acknowledge that a number of other factors that were not considered in our analysis also contribute to accidents/incidents at grade crossings (e.g., driving style, driving skill, impairment due to distraction, fatigue, or alcohol use). Rather, the purpose of this analysis was to "test" the results of our model with the findings of Horton et al. to better understand how a descriptive model may be useful in examining

Table 2. Percent reduction of incidents for each isolated safety factor.

\begin{tabular}{ll}
\hline Factor & Reduction \\
\hline Improving commercial motor vehicle driver safety & $34.6 \%$ \\
Increasing locomotive conspicuity through the use of alerting lights & $13.6 \%$ \\
Increasing sight lines & $3.6 \%$ \\
Improving warning device reliability & $3.1 \%$ \\
Improving the reliability of motor vehicles & $3.1 \%$ \\
\hline
\end{tabular}


grade-crossing safety. A descriptive model provides a description of a phenomenon that is consistent with established theory and pertinent data and can be used to organize information and clarify relationships between variables. The model proposed here was intended to describe driver behavior at grade crossings with respect to SDT and to determine the contribution of five safety factors to driver decision making at grade crossings. If this effort was successful, then the model could be applied to examine other safety factors.

In considering the five safety factors listed in Table 2, we expected that two would exert a primary influence on sensitivity (the use of alerting lights and increasing sight lines) and two would influence bias (improving CMV driver safety regulations and improving warning device reliability). We did not expect the fifth safety factor improving the reliability of motor vehicles to influence driver decision making because it was measured on the basis of whether an accident involved a car that had a mechanical failure or stalled on the highway tracks. Instead, we added another factor that we expected to influence sensitivity-the use of reflectors to increase rail car conspicuity.

Although we distinguish the five safety factors according to how they were expected to influence sensitivity and bias, we did not expect that the two measures would change independently. Rather, we expected that a change in one would have an observable effect on the other. For example, by improving the signal-to-noise ratio of the train at a grade crossing (sensitivity), the train is more detectable and thus drivers may be more likely to stop. Conversely, by encouraging drivers to be more cautious at a grade crossing (bias), drivers may take more time and effort to look for a train, thereby increasing sensitivity.

\section{Method}

We estimated $\mathrm{d}^{\prime}$ and $\beta$ for five safety factors using the definitions below. These definitions were derived based on the data fields available from the Highway-Rail Grade Crossing Accident/Incident database. The definitions for the first four were developed by Horton et al. (2008) in their analysis. The fifth safety factor, improving rail car conspicuity through the use of reflectors, was defined by Carroll et al. (1995).

- Improving CMV driver safety through federal regulations: Accidents associated with this safety factor resulted from a motor vehicle that would require a Commercial Drivers' License (CDL).

- Increasing rail car conspicuity with alerting lights: This safety factor was defined by accidents in which rail equipment struck a motor vehicle either at dusk, dawn, or dark (i.e., train strikes car); the time of day is important because the use of alerting lights provides more benefit at night than during the day. Alerting lights are located on the locomotive.

- Increasing sight lines: The accidents associated with this safety factor noted one of five categories of visual obstruction at the grade crossing: permanent structure, standing railroad equipment, topography, vegetation, and other. 
- Improving warning device reliability: The accidents associated with this safety factor occurred at grade crossings with active warning devices and resulted for one of three reasons: the warning signal malfunctioned; the malfunctions consisted of alleged and confirmed warning times that were too long or too short; or no warning was presented.

- Increasing train conspicuity with reflectors: This safety factor was defined by accidents in which rail equipment was struck by a motor vehicle either at dusk, dawn, or dark (i.e., car strikes train). Reflectors are located on rail cars.

For our analysis, we focused on grade-crossing safety in the years from 1986 to 2007. The year 1986 was selected as a baseline for consistency with Raslear (1996). Additionally, none of the safety factors had been introduced at that time. The year 2007 was used because it was the most recent year for which data was available when this analysis was performed. The one exception was the analysis for "improving warning device reliability." In 1997, the FRA modified its reporting structure associated with the reporting of that safety factor to include five additional criteria; as a result of that change, more accidents were identified that were attributed to that safety factor. Because the data fields for warning device reliability was different between 1986 and 2007, we chose instead to use the year 1997 (the first year in which the new criteria were used) as the baseline for that safety factor.

We evaluated changes in driver decision making for each safety factor by estimating sensitivity and bias for eight grade-crossing warning devices: no protection, other signs or signals, crossbuck, stop sign, special warning devices, other activated warning devices (e.g., highway traffic signals, wigwags), flashing lights, and gates. We estimated sensitivity using $\mathrm{d}^{\prime}$, which was calculated as

$$
\mathrm{d}^{\prime}=\mathrm{z}[\mathrm{P}(\mathrm{VS})]-\mathrm{z}[\mathrm{P}(\mathrm{FS})]
$$

In the formula, $\mathrm{P}(\mathrm{VS})$ is the probability of a valid stop (a hit), and $\mathrm{P}(\mathrm{FS})$ is the probability of a false stop (a false alarm). $\mathrm{d}^{\prime}$ is the difference between the standardized $\mathrm{z}$-score of $\mathrm{P}(\mathrm{VS})$ and the standardized $\mathrm{z}$-score of $\mathrm{P}(\mathrm{FS})$.

We estimate bias using $\beta$ and calculated it as

$$
\begin{gathered}
\beta=\frac{y(V S)}{y(F S)}, \text { where } \\
y(V S)=0.3989 e^{-z[P(V S)]^{2} / 2}, \text { and } \\
y(F S)=0.3989 e^{-z[P(F S)]^{2} / 2}
\end{gathered}
$$

An overview of the calculations is presented here. Additional details and formulas are provided in Raslear (1996).

We estimated values for $\mathrm{P}(\mathrm{VS})$ and $\mathrm{P}(\mathrm{FS})$ using accident data for each of the eight warning devices for each safety factor. By definition, $\mathrm{P}(\mathrm{VS})+\mathrm{P}(\mathrm{AC})=1$. Therefore, $\mathrm{P}(\mathrm{VS})$ is equal to 1 minus the probability of an accident (i.e., $1-\mathrm{P}$ 
(AC)), where $\mathrm{P}(\mathrm{AC})$ was defined to be the accident rate for each safety factor per crossing per train per highway vehicle per minute to equalize for exposure.

$\mathrm{P}(\mathrm{FS})$ was not as straightforward to define as $\mathrm{P}(\mathrm{VS})$. Rather, we estimated the probability of a correct crossing, $\mathrm{P}(\mathrm{CC})$, and then calculated $\mathrm{P}(\mathrm{FS})$ as 1 minus $\mathrm{P}$ (CC). $\mathrm{P}(\mathrm{CC})$ reflects the probability that a car and a train will arrive at the crossing at the same time and that one (or both) will stop. Data to estimate $\mathrm{P}(\mathrm{CC})$ directly was not available, but we could estimate the reverse; that is, the probability that a car and a train will arrive at the grade crossing at the same time and that neither can stop. We described this estimate as the maximum accident risk at a grade crossing, $\mathrm{P}(\mathrm{AC})_{\max } \mathrm{P}(\mathrm{CC})$ is thus equal to 1 minus $\mathrm{P}(\mathrm{AC})_{\max }$, and $\mathrm{P}(\mathrm{FS})$ is equal to the accident risk associated with each warning device. That is,

$$
\begin{gathered}
\mathrm{P}(\mathrm{FS})=1-\mathrm{P}(\mathrm{CC})=1-\left[1-\mathrm{P}(\mathrm{AC})_{\max }\right]=\mathrm{P}(\mathrm{AC})_{\max } \text { and } \\
\mathrm{P}(\mathrm{AC})_{\max }=\mathrm{P}(\text { Train }) \times \mathrm{P}(\text { Highway Vehicle }) .
\end{gathered}
$$

where,

$\mathrm{P}($ Train $)=$ the probability that one or more trains would be observed at a grade crossing in a 1-minute period

$\mathrm{P}($ Highway Vehicle $)=$ the probability that one or more highway vehicles would be observed at a grade crossing in a 1-minute period.

The values for $\mathrm{P}$ (Train) and $\mathrm{P}$ (Highway Vehicle) can be estimated using the train rate per day at a crossing and the AADT at a crossing, respectively.

The data needed to calculate $\mathrm{P}(\mathrm{AC})$ and $\mathrm{P}(\mathrm{AC})_{\max }$ were provided in the FRA's Highway-Rail Crossing Inventory. This database contains a list of all grade crossings, the warning devices used at those crossings, the median number of trains per day for the crossings, and the median AADT at the crossings. However, because the fields for trains per day and AADT in the Highway-Rail Crossing Inventory were not updated each year, we adjusted our estimate for these values to more accurately reflect the increase in the overall number of trains and highway vehicles from 1986 to 2007 . The increase in the number of trains was estimated by dividing the number of train miles traveled with the number of track miles for each year from 1986 through 2007 based on data provided by the FRA and the Association of American Railroads. The increase in the number of highway vehicles was estimated according to information on national vehicle miles travelled (VMT) from 1986 through 2007. The number of trains per day and AADT was not changed for 1986, but the values for 2007 were proportionally increased to reflect the changes. (See Yeh et al., 2009, for more details regarding this adjustment.) It is worthwhile to note that the adjustments in train and vehicle traffic growth was used an aggregate level in this analysis; consequently, this method may not be appropriate when examining individual grade crossings as the rate of this growth will vary depending on specific characteristics of the grade crossing.

There were several warning devices for which there were no accidents attributable to one or more of the safety factors we identified in one or both of the years 
Table 3. Warning device data swap by safety factor.

\begin{tabular}{lll}
\hline Safety Factor & Lender & \multicolumn{1}{c}{ Borrower } \\
\hline Commercial motor vehicle driver safety & Crossbuck & Other signs or signals \\
Alerting lights & Crossbuck & Other signs or signals \\
Reflectors & Crossbuck & No signs or signals \\
& Stop Signs & Other signs or signals \\
Sight lines & Crossbuck & No signs or signals \\
& Stop signs & Other signs or signals \\
& Flashing lights & Highway traffic signals, wigwags, \\
& & bells, or other activated warning device \\
\hline
\end{tabular}

we examined. To estimate $\mathrm{d}^{\prime}$ and $\beta$ when no accidents existed, we conducted a data swap by borrowing an accident from a similar warning device (e.g., if we did not have data for one passive warning device, we would borrow from another passive warning device). The number of accidents for the borrower would equal 1, allowing a value to be calculated for $\mathrm{d}^{\prime}$ and $\beta$, although these estimates would not be as large as it would have been if a value could be determined for no accidents. The warning device from which the accident was borrowed (the lender) would have one less accident, which could result in a slight increase in the estimate for $\mathrm{d}^{\prime}$ and a slight decrease in the estimate for $\beta$. The lender and borrower are noted in Table 3.

\section{Results}

Figures showing the estimates for $\mathrm{d}^{\prime}$ and the natural logarithm (ln) $\beta$ are described for each safety factor. Because $\beta$ is nonlinear, the changes are better depicted by transforming the estimates using the natural logarithm. For each safety factor, estimates of $\mathrm{d}^{\prime}$ and $\ln \beta$ were compared using a 2 (year) $\times 8$ (warning device) ANOVA conducted using the SAS/STAT statistical analysis software. Because we only had one observation per cell, the ANOVA model included only the main effects. We also calculated $\omega^{2}$ to determine the amount of variance accounted for by each independent variable and conducted paired comparisons using SAS/STAT to identify differences among the warning devices. Full details of the analysis and the results are described in Yeh et al. (2013).

\subsection{CMV driver safety}

Figure 2 shows the estimates for $\mathrm{d}^{\prime}$ (bars) and $\ln \beta$ (lines) for accidents involving a CMV driver. The estimates for 2007 reflect the results of a data swap in which one accident was borrowed from the crossbuck and lent to other signs or signals.

Regulations to improve CMV driver safety contributed to a significant 0.29-point increase in sensitivity from 1986 to $2007, F(1,7)=16.93, p<.05, \omega^{2}=.24$. Estimations of $\mathrm{d}^{\prime}$ also differed significantly depending on the warning device, $F(7,7)=6.11, p<.05$, $\omega^{2}=.53$. The results of paired comparisons indicated that drivers at stop-sign protected crossings were least sensitive but showed the largest increase in sensitivity for this safety factor over the period examined (0.67 points). Drivers were most sensitive at grade crossings with no protection or those with special active warning devices. 


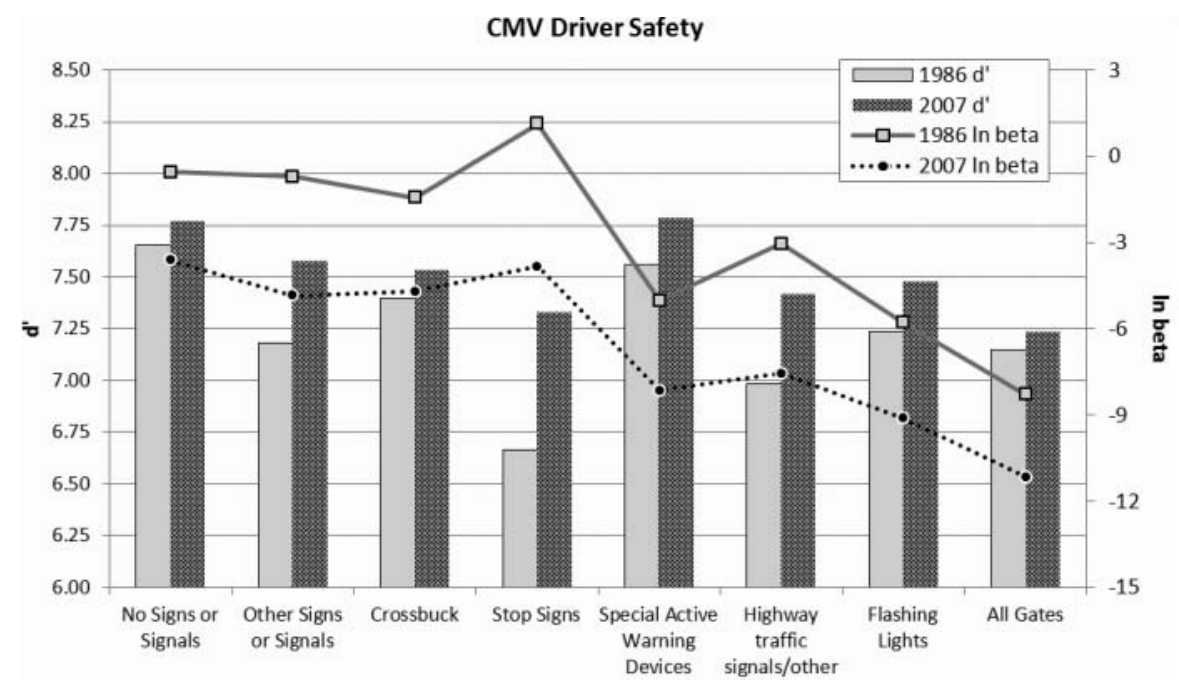

Figure 2. CMV driver safety.

We had expected that regulations to improve driver safety would encourage drivers' to change their behavior, and estimations of $\ln \beta$ showed that this indeed was the effect. The data showed a significant conservative shift from -2.96 in 1986 to -6.62 in $2007, \ln \beta: F(1,7)=180.39, p<.05, \omega^{2}=.30$. The inclination to stop differed depending on the warning device, $\ln \beta: F(7,7)=59.11, p<.05, \omega^{2}=.68$; the results of paired comparisons showed that drivers exhibited the most conservative behavior at crossings protected by gates, and the riskiest behavior at crossings protected by passive warning devices.

\subsection{Alerting lights}

Figure 3 shows the estimates for $\mathrm{d}^{\prime}$ and $\ln \beta$ using the total number of accidents with visibility conditions that could be ameliorated by alerting lights. The estimates for 2007 reflect the results of a data swap in which one accident was borrowed from the crossbuck and used to derive estimates of $\mathrm{d}^{\prime}$ and $\beta$ for other signs or signals.

The number of accidents with visibility conditions that could be addressed through the installation of alerting lights on the train decreased from 1986 to 2007. This decrease in the number of accidents was reflected in a significant 0.31-point increase in $\mathrm{d}^{\prime}, F(1,7)=20.30, p<.05, \omega^{2}=.25$. There was also a significant difference in $\mathrm{d}^{\prime}$ attributable to warning device, $F(7,7)=6.90, p<.05, \omega^{2}=.54$, such that estimations for $\mathrm{d}^{\prime}$ were highest for crossings with no signs or signals and those protected by special active warning devices and lowest for crossings protected by gates or those with stop signs.

The use of alerting lights was expected to have a positive impact on $\mathrm{d}^{\prime}$, but the data also showed a conservative shift in $\ln \beta$ from -2.95 in 1986 to -6.72 in 2007, 


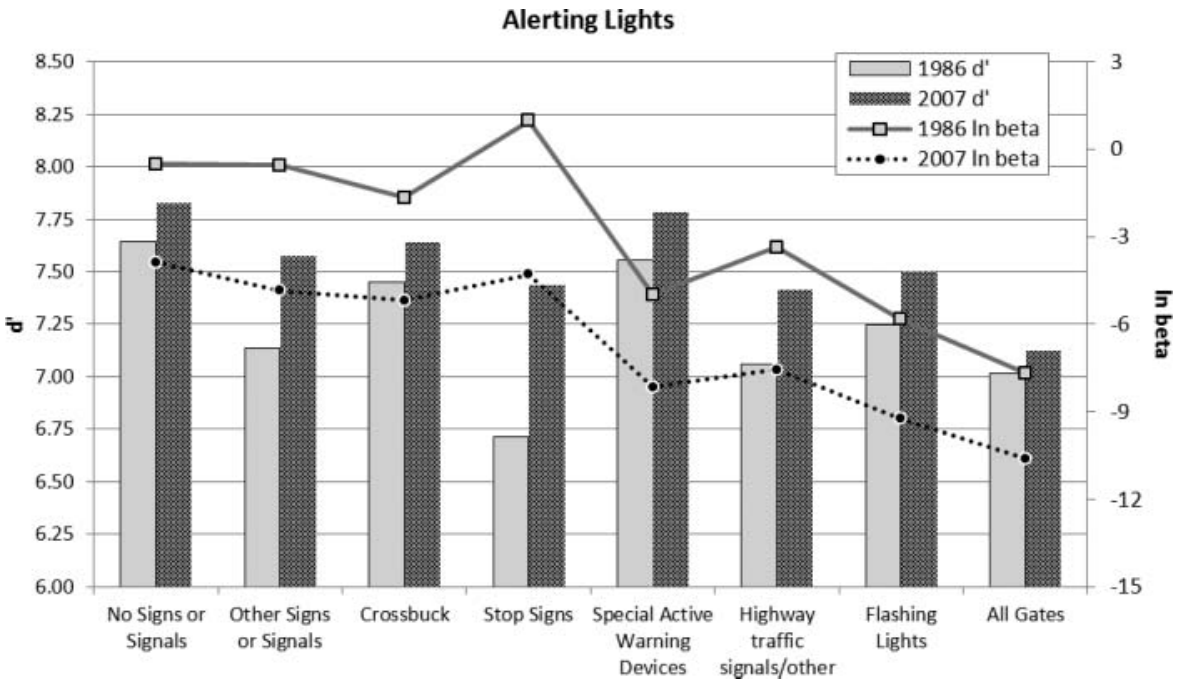

Figure 3. Alerting lights.

$F(1,7)=201.08, p<.05, \omega^{2}=.34$. The type of warning device also had a significant influence on drivers' tendencies to stop or proceed, $\ln \beta: F(7,7)=53.85, p<$ $.05, \omega^{2}=.63$. Although it is not clear which warning device benefited the most from the use of alerting lights, the results of the paired comparisons suggest that drivers were more likely to stop at crossings with active warning devices than those with passive warning devices.

\subsection{Reflectors}

Figure 4 shows the estimates for $\mathrm{d}^{\prime}$ and $\beta$ using accidents with visibility conditions that could be addressed by reflectors. There were no accidents at grade crossings protected by "no signs or signals" or "other signs or signals" in 2007, so the estimates for 2007 reflect the results of two data swaps. One accident each was borrowed from two categories (crossbuck and stop signs) and loaned to no signs or signals and other signs or signals to derive an estimates of $\mathrm{d}^{\prime}$ and $\beta$.

The use of reflectors is intended to improve the detectability of a train, so it was expected to improve driver sensitivity. Estimations of $\mathrm{d}^{\prime}$ increased by 0.19 from 1986 to 2007 , but this difference was only marginally significant, $F(1,7)=4.59, p$ $<.10, \omega^{2}=.09$. Rather, the type of warning device appeared to account for more of the change in $\mathrm{d}^{\prime}, F(7,7)=4.18, p<.05, \omega^{2}=.53$. Drivers were most sensitive at grade crossings protected by no signs or signals (an average of 8.10 ) and less sensitive at grade crossings protected by gates, stop signs, or highway traffic signals, wigwags, bells, or other activated warning device. The data also suggests that drivers were less sensitive at grade crossings protected by "no signs or signals" in 2007 than in 1986, despite the lack of reflectorization. However, we believe that this difference is a reflection of the low number of accidents attributable to the use of 


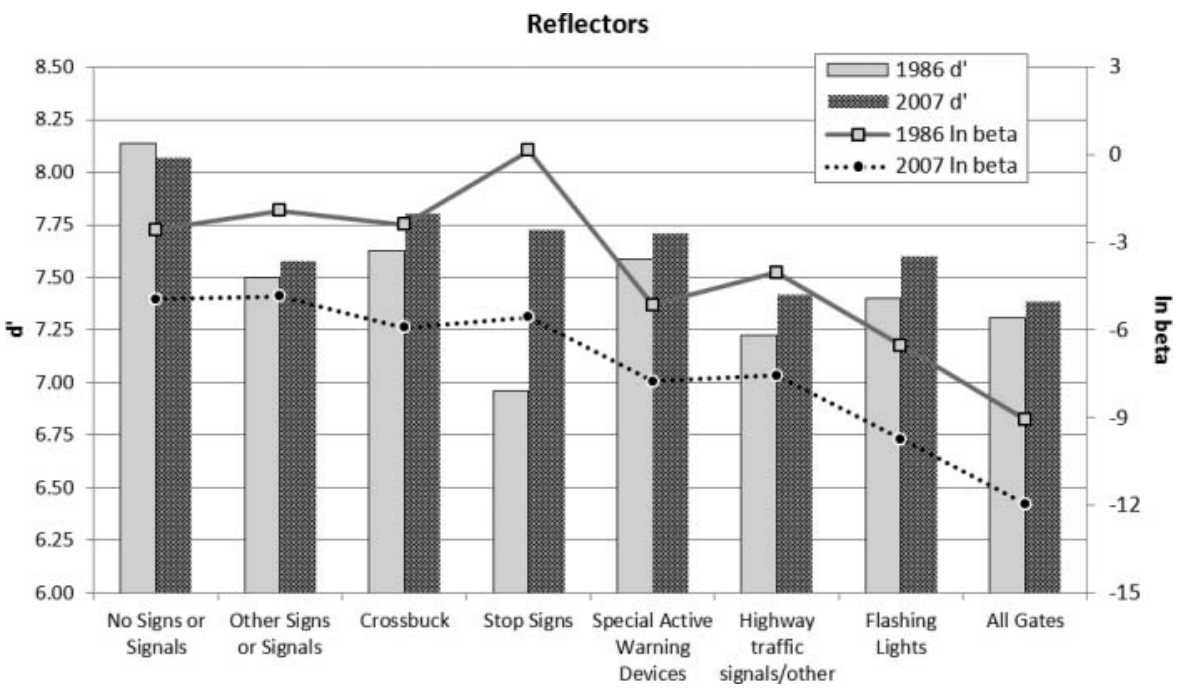

Figure 4. Reflectors.

reflectors and to the increase in accident risk from 1986 to 2007. Data from the Highway-Rail Grade Crossing Accident/Incident database shows three accidents at grade crossings with no signs or signals in 1986 and none in 2007. However, our estimations of accident risk showed that accident risk was three times greater in 2007 than in 1986.

The use of reflectors also led to a significant drop in $\ln \beta$ from -3.93 in 1986 to -7.27 in 2007, $F(1,7)=79.39, p<.05, \omega^{2}=.29$. Estimations of $\ln \beta$ also differed significantly by warning device, $F(7,7)=25.09, p<.05, \omega^{2}=.64$. The pattern of results suggest that drivers were more likely to stop at crossings protected by gates and flashing lights than other warning devices, and drivers were more inclined to proceed at crossings with passive warning devices or at active crossings with highway traffic signals, wigwags, bells, or other activated warning device.

\subsection{Increasing sight lines}

Figure 5 presents the estimates for $\mathrm{d}^{\prime}$ and $\beta$ using accidents with visibility conditions that could be reduced by improving sight lines. Three swaps were needed to calculate estimates for 2007; in that year, there were no accidents attributable to the sight lines safety factor for several warning devices: no signs or signals, other signs or signals, or highway traffic signals, wigwags, bells, or other activated warning device. Thus, in the swap, one accident was borrowed from the crossbuck, stop signs, and flashing lights and loaned to no signs or signals, other signs or signals, and highway traffic signals, wigwags, bells, or other activated warning device categories, respectively. (The accidents for passive warning devices were borrowed from other passive warning devices, and the accidents for active warning devices were borrowed from other active warning devices.) 


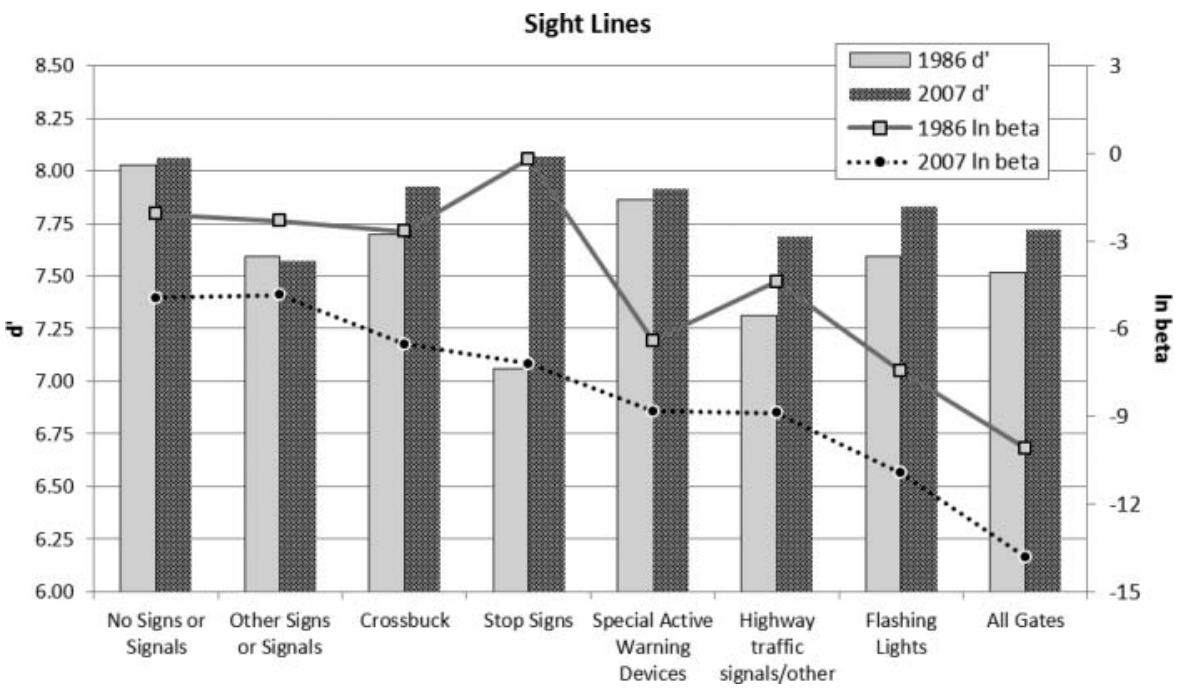

Figure 5. Increasing sight lines.

Clearing obstructions to sight lines at grade crossings was expected to increase drivers' sensitivity to a train. In fact, this was the case; estimates of $\mathrm{d}^{\prime}$ increased by 0.27 points from 1986 to $2007, F(1,7)=5.36, p=.05, \omega^{2}=.19$. Estimations of $\mathrm{d}^{\prime}$ did not differ by warning device, $F(7,7)=1.3, p>.10$.

Although clearing sight lines had a smaller impact on estimations of $d^{\prime}$ than expected, estimations of $\ln \beta$ improved significantly as well in the same time period, from -4.45 in 1986 to -8.24 in $2007, F(1,7)=52.85, p<.05, \omega^{2}=.28$. Estimations of $\ln \beta$ also differed significantly by warning device, $F(7,7)=17.59$, $p<.05, \omega^{2}=.63$. The results of paired comparisons suggested that drivers were more inclined to stop at grade crossings protected by gates or flashing lights than at crossings protected by any of the six other warning devices. The largest change in the time period examined was at grade crossings protected by stop signs and the smallest change was at grade crossings with gates.

\subsection{Warning device reliability}

In 1986, the FRA collected information on warning device reliability using only two criteria: that a warning device provided the minimum 20-sec warning, or that no warning was given. This reporting resulted in 26 total accidents in the Highway-Rail Grade Crossing Accident/Incident database for that year. In 1997, the FRA added additional criteria to judge warning device reliability so that this safety factor was measured as follows:

1. The warning device provided the minimum 20-sec warning.

2. The warning device had an alleged warning time greater than $60 \mathrm{sec}$.

3. The warning device had an alleged warning time fewer than $20 \mathrm{sec}$. 
4. The warning device allegedly presented no warning.

5. The warning device had a confirmed warning time greater than $60 \mathrm{sec}$.

6. The warning device had a confirmed warning time fewer than $20 \mathrm{sec}$.

7. The warning device presented no warning (confirmed).

As noted previously, we were concerned that comparing driver decision making as a function of warning device reliability for the years 1986 and 2007 would be misleading given the inconsistency in the information collected. We chose instead to compare the 2007 data to information collected in 1997 (the first year in which the new criteria were used). Figure 6 presents the estimates for $\mathrm{d}^{\prime}$ and $\ln \beta$ using accidents attributable to warning device reliability for the four active warning devices. One swap was needed to calculate the estimates. There were no accidents at grade crossings protected by special active warning devices in either year, so one accident was borrowed from the flashing lights warning device.

Estimations of $\mathrm{d}^{\prime}$ did not change significantly from 1997 (7.61) to 2007 (7.74), F $(1,3)=2.19, p>.05$. The effect of warning device on $\mathrm{d}^{\prime}$ was significant, however, $F(3,3)=11.81, p<.05, \omega^{2}=.78$, such that drivers at crossings protected with special active warning devices had a higher sensitivity than at the other active warning devices.

Estimations of $\ln \beta$ suggest that our hypothesis that improvements in warning device reliability would improve drivers' inclination to stop was correct; In $\beta$ dropped from -9.07 in 1997 to -10.32 in $2007, \ln \beta: F(1,3)=12.16, p<.05$, $\omega^{2}=.19$. A significant main effect of warning device was also present, $\ln \beta: F(3,3)$ $=14.5, p<.05, \omega^{2}=.68$, with the most conservative behavior exhibited at crossings protected by gates and the riskiest behavior at crossings with highway traffic signals, wigwags, bells, or other activated warning device.

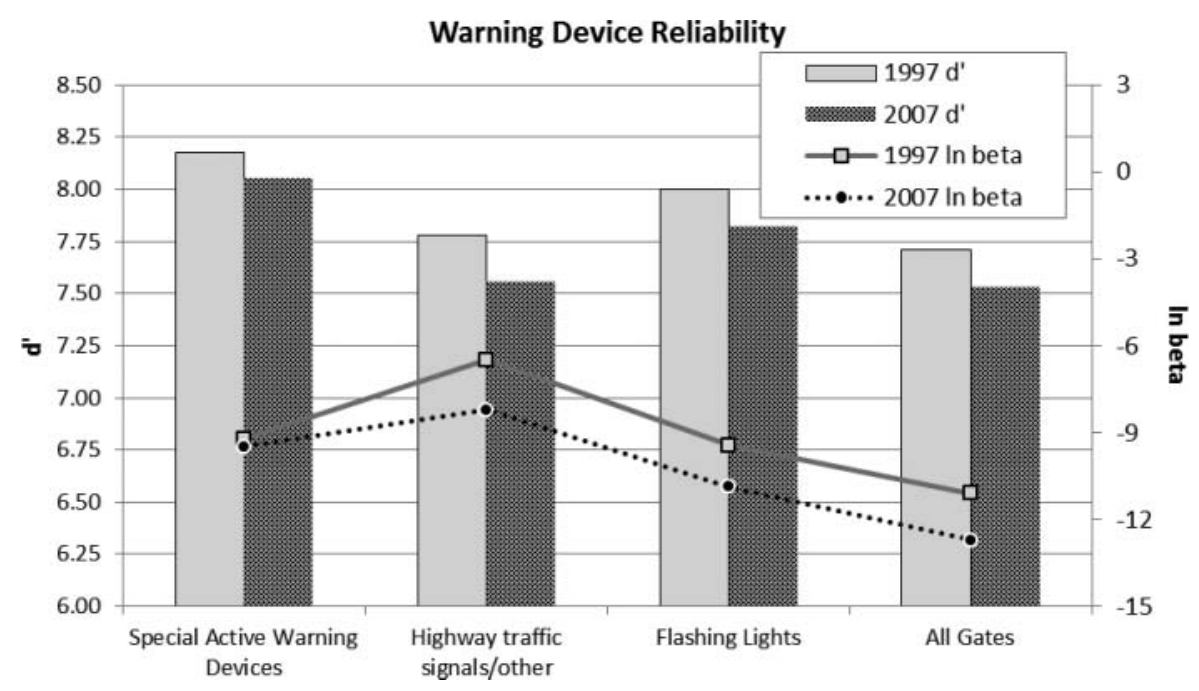

Figure 6. Warning device reliability. 


\section{Summary}

In the time period from 1986 to 2007 , mean $\mathrm{d}^{\prime}$ changed significantly by $3.2 \%$ as a result of introducing the safety factors, whereas mean $\beta$ increased by $165 \%$, for $\mathrm{d}^{\prime}$, $t(4)=7.04, p<.01$; for $\ln \beta, t(4)=10.27, p<.01$. The proportion of variance accounted for $\left(\omega^{2}\right)$ by the safety factor and device type, as calculated from the twoway ANOVAs that were performed to examine the statistical reliability of the changes in $\mathrm{d}^{\prime}$ and $\ln \beta$ accruing to the introduction of the safety factor and of the grade-crossing device type (collectively called grade-crossing safety) are shown in Table 4.

Although the analyses presented so far suggests that $\ln \beta$ played a much larger role in enhancing safety through the introduction of the safety factors, it is difficult to directly compare $\mathrm{d}^{\prime}$ and $\ln \beta$ because the estimates of $\mathrm{d}^{\prime}$ range from a minimum of 0 to infinity (i.e., $0 \leq \mathrm{d}^{\prime} \leq \infty$ ), but the estimates of $\ln \beta$ can range from negative infinity to positive infinity (i.e., $-\infty \leq \ln \beta \leq \infty$ ). The use of $\omega^{2}$ to indirectly compare $\mathrm{d}^{\prime}$ and $\ln \beta$ can avoid this problem because $\omega^{2}$ indicates the strength of the association between a dependent variable $\left(\mathrm{d}^{\prime}\right.$ or $\left.\ln \beta\right)$ and an independent variable (a safety factor) in a unit-less metric (Hays, 1963, p. 325). Thus, a two-way nonparametric ANOVA was performed on the $\omega^{2}$ data to determine if the differences in strength of association between $\mathrm{d}^{\prime}$ and $\ln \beta$, between safety factors and device types, and their interaction were reliable (see Bradley, 1968). The mean $\omega^{2}$ for $\mathrm{d}^{\prime}$ is 0.306 , while for $\ln \beta$ it is 0.466 . The difference in $\omega^{2}$ between $\mathrm{d}^{\prime}$ and $\ln \beta$ was statistically reliable (Wilcoxon Signed Rank Test, $p=.0313$ ), indicating that the association between bias and grade crossing safety was $50 \%$ greater than that for $\mathrm{d}^{\prime}$. In other words, the overall improvement in safety was due to increases in ability to detect a train and a bias to stop, but a bias to stop was $50 \%$ more important.

The mean $\omega^{2}$ is 0.208 for safety factor and 0.564 for device type. This difference in $\omega^{2}$ is also statistically reliable (Wilcoxon Signed Rank Test, $p=.0313$ ), indicating that the association between device type and grade-crossing safety was 1.7 times greater than that for safety factor. That is, the overall improvement in safety was due to grade-crossing devices and safety factors, but grade-crossing devices were nearly twice as important.

Table 4. Statistical summary of the successful safety factors.

\begin{tabular}{llllll}
\hline & \multicolumn{2}{c}{$\omega^{2}\left(\mathrm{~d}^{\prime}\right)$} & & \multicolumn{2}{c}{$\omega^{2}(\ln \beta)$} \\
\cline { 2 - 3 } Safety Factor & Safety Factor & Device & & Safety Factor & Device \\
\hline Commercial motor vehicle driver safety & 0.24 & 0.53 & & 0.3 & 0.68 \\
Alerting lights & 0.25 & 0.54 & & 0.34 & 0.63 \\
Reflectorization & 0 & 0.53 & 0.29 & 0.64 \\
Sight lines & 0.19 & 0 & 0.28 & 0.63 \\
Warning reliability & 0 & 0.78 & 0.19 & 0.68 \\
Average & 0.136 & 0.476 & 0.28 & 0.652 \\
\hline
\end{tabular}




\section{Discussion}

The results of our analysis show statistically significant improvements in driver decision making (as estimated by $\mathrm{d}^{\prime}$ and $\ln \beta$ ) attributable to the warning device type and the introduction of the safety factor. Of the two, the analysis comparing $\omega^{2}$ suggests that warning devices had the most impact on grade-crossing safety because they encourage drivers to stop at grade crossings. This bias to stop is more important than improving the driver's ability to detect the train, and even measures to improve train detection improve driver's bias to stop. Regulations to improve CMV driver safety, the use of alerting lights, sight lines, and reflectors were generally equally effective in improving grade-crossing safety. Warning device reliability (which pertained to active warning devices only) still contributed to improvements in grade-crossing safety, but the effects were more muted.

The results show that the patterns in $\mathrm{d}^{\prime}$ and $\beta$ for grade-crossing devices are similar across safety factors. This is because the decision concerning the type of grade-crossing device to use at a particular location is determined largely by the volume of train and highway traffic at that location. Grade crossings with low train and highway traffic would have passive devices installed. Active devices are used at crossings with high volumes of train and highway traffic. The level of accident risk for a grade crossing determines the type of grade-crossing device used at that crossing. Active devices provide more bias to stop than passive devices. Active devices also produce more noise at the grade crossing, thereby decreasing the signal to noise ratio $(\mathrm{S} / \mathrm{N})$ and train detectability. In fact, the analysis shows that drivers were more sensitive but least likely to stop at grade crossings with "no signs and signals." The lack of signs and markings reduce the signal-to-noise ratio at the grade crossing, allowing drivers to be more sensitive to the presence of a train, but at the same time, there is no information at the grade crossing to encourage stoppings.

The findings from our analysis differ from those reported by Horton et al. (2008) who evaluated the impact of these safety factors as a function of the change in the number of accidents. Table 5 shows a comparison of the estimates by Horton et al. and the mean $\omega^{2}$ values calculated in the analysis reported here (across SDT metric).

The table highlights that with the exception of CMV driver safety, our data showed greater contributions for each of the safety factors examined than that reported by Horton et al. (2008). We acknowledge that our approaches to analysis

Table 5. Comparison of safety factors between Horton et al. (2008) and this report.

\begin{tabular}{lcc}
\hline Safety Factor & Accident Reduction (\%) & Mean $\omega^{2} \times 100(\%)$ \\
\hline Commercial motor vehicle driver safety & 34.6 & 27 \\
Alerting lights & 13.6 & 29.5 \\
Sight lines & 3.6 & 23.5 \\
Warning reliability & 3.1 & 9.5 \\
\hline
\end{tabular}


and the timeframe we considered in our analyses differed. Horton et al. calculated the percent reduction by determining the percent change in the number of incidents attributable to the safety countermeasure for the 10-year time-period from 1994 to 2003 (i.e., the change in the number of incidents for a safety factor from 1994 to 2003 divided by the total number of grade-crossing incidents from 1994 to 2003). Rather than use accident frequency as in Horton et al., our SDT model estimated metrics describing driver sensitivity and bias, which were derived using a Poisson distribution of the accident rate and examined data for a 21-year time period from 1986 to 2007. The Poisson distribution (as we used it here) is often used to model accident frequencies because accidents are rare events and so may be better described using Poisson probabilities than accident rate alone. In other words, analysis of the accident rate alone may not be a good way to assess safety or determine the significance of the change in accident rate.

The findings offer recommendations for improving grade-crossing safety as well as areas where additional research is needed. In particular, the results suggest that the greatest benefits may be obtained for those countermeasures that encourage drivers to stop at the crossing, such as legislation requiring CMV drivers to stop at all grade crossings. The results also point to research to evaluate the effectiveness of other warning devices for use at grade crossings. In particular, data is needed to predict and understand the potential effect of highway intersection-related traffic control devices such as yield signs at passive grade crossings and traffic signals, which are less expensive to install than traditional grade-crossing active warning devices.

Based upon our current efforts, we believe that the SDT model provides a descriptive framework that can be applied to understand the impact of other countermeasures for improving grade-crossing safety and can be refined with field studies or laboratory experiments to better characterize driver decision making. Additionally, we believe that the results are more informative than that offered by more "traditional" analyses, such as accident analyses because the framework considers accident frequency with respect to human behavioral metrics that influence driver decision making. In fact, the analysis shown here suggests that the examination of accident frequency alone is misleading and may minimize the impact of other important safety factors.

\section{Notes}

1. A value of $\beta$ equal to 1 represents no bias, a value of $\beta$ less than 1 indicates a willingness to stop, and a value of $\beta$ greater than 1 indicates an inclination to proceed.

2. The Federal Motor Carrier Safety Administration (FMCSA) suspends Commercial Drivers' Licenses (CDL) for commercial motor vehicle (CMV) drivers who violate grade-crossing warning devices and imposes penalties against any motor carrier who knowingly allowed, permitted, authorized, or required a CMV driver to commit such a violation (e.g., see 49 CFR 383.51(d), Disqualification for railroad-highway grade crossing offenses). 


\section{Acknowledgments}

The views expressed herein are those of the authors and do not necessarily reflect the views of the John A. Volpe National Transportation Systems Center, the Research and Innovative Technology Administration, or the United States Department of Transportation.

\section{Funding}

This research was conducted with funding from the Federal Railroad Administration's Office of Research and Development while Michelle Yeh was a staff member at the Volpe National Transportation Systems Center.

\section{References}

Bradley, J. V. (1968). Distribution-free statistical tests. Englewood Cliffs, NJ: Prentice-Hall.

Carroll, A. A., Multer, J., \& Markos, S. H. (1995). Use of auxiliary external alerting devices to improve locomotive conspicuity. Cambridge, MA: US Department of Transportation/Federal Railroad Administration.

Commercial Driver Disqualification Provision; 49 CFR Parts 383 and 384; Final rule; published: 09/02/99; Effective Date: 10/04/99; [FHWA Docket No. FHWA-97-3103]; 64 FR 48104.

Egan, J. P. (1975). Signal detection theory and ROC analysis. New York, NY: Academic.

Green, D. M., \& Swets, J. A. (1966). Signal detection theory and psychophysics (Rev. ed.). New York, NY: Wiley.

Hays, W. L. (1963). Statistics for psychologists. New York: Holt, Rinehart and Winston.

Horton, S., Carroll, A., Chaudhary, M., Ngamdung, T., Mozenter, J., \& Skinner, D. (2008). Success factors in the reduction of highway-rail grade crossing incidents from 1994 to 2003. Cambridge, MA: U.S. Department of Transportation, Research and Innovative Technology Administration, Volpe Center.

Mortimer, R. (1988). Human factors in highway-railroad grade crossing accidents. In G. A. Peters \& B. J. Peters (Eds.), Automotive engineering and litigation (Vol. 2, pp. 35-69). New York, NY: Garland Law Publishing.

Office of the Inspector General. (2004). 2004 Audit of the Highway-Rail Grade Crossing Safety Program (Report Number: MH-2004-065). Washington, DC: Federal Railroad Administration, Office of the Inspector General.

Raslear, T. G. (1996). Driver behavior at rail-highway grade crossings: A signal detection theory analysis. In A. A. Carroll \& J. L. Helser (Eds.), Safety of highway-railroad grade crossings. Research needs workshop. Volume II - Appendices (Report No. DOT/FRA/ORD-95/14.2, DOT-VNTSC-FRA-95-12.2, pp. F9-F56). Washington, DC: U.S. Department of Transportation.

Yeh, M., Multer, J., \& Raslear, T. (2009). An application of signal detection theory for understanding driver behavior at highway-rail grade crossings. In Proceedings of the Human Factors and Ergonomics Society 53rd Annual Meeting. Santa Monica, CA: Human Factors and Ergonomics Society.

Yeh, M., Raslear, T., \& Multer, J. (2013). Understanding driver behavior at grade crossings through signal detection theory (DOT/FRA/ORD-13/01). Cambridge, MA: U.S. Department of Transportation, Volpe National Transportation Systems Center. 